\section{Editorial}

Check for updates

\section{OPEN ACCESS}

Received: Oct 28, 2019

Accepted: Nov 4, 2019

Correspondence to

Luo Zhang, MD, PhD

Beijing Institute of Otolaryngology, Department of Otolaryngology Head and Neck Surgery, Beijing TongRen Hospital, Capital Medical University, No. 17, Hougou Hutong, Dongcheng District, Beijing 100730, China.

Tel: +86-10-65141136

Fax: +86-10-85115988

E-mail: dr.luozhang@139.com

Copyright (c) 2020 The Korean Academy of Asthma, Allergy and Clinical Immunology . The Korean Academy of Pediatric Allergy and Respiratory Disease

This is an Open Access article distributed under the terms of the Creative Commons Attribution Non-Commercial License (https:// creativecommons.org/licenses/by-nc/4.0/) which permits unrestricted non-commercial use, distribution, and reproduction in any medium, provided the original work is properly cited.

Disclosure

There are no financial or other issues that might lead to conflict of interest.

\title{
Understanding the Role of Neutrophils in Refractoriness of Chronic Rhinosinusitis With Nasal Polyps
}

\section{Feng Lan, ${ }^{1,2}$ Luo Zhang ${ }^{1,2^{*}}$}

'Department of Otolaryngology Head and Neck Surgery, Beijing TongRen Hospital, Capital Medical University, Beijing, China

${ }^{2}$ Beijing Key Laboratory of Nasal Disease, Beijing Institute of Otolaryngology, Beijing, China

- See the article "Elastase-Positive Neutrophils Are Associated With Refractoriness of Chronic Rhinosinusitis With Nasal Polyps in an Asian Population” in volume 12 on page 42.

Chronic rhinosinusitis with nasal polyps (CRSwNP) is a highly heterogeneous mucosal inflammatory condition of the nose and paranasal sinuses, which affects about $2 \%-8 \%$ of the population in the world. ${ }^{1-3} \mathrm{CRSwNP}$ is further divided into 5 phenotypic clusters, based on the dominant inflammatory cell types infiltrating the tissue; including a plasma celldominant phenotype, a lymphocyte-dominant phenotype, a mixed inflammation phenotype, a neutrophil-dominant phenotype, and an eosinophil-dominant phenotype. ${ }^{4}$ Eosinophilic CRSwNP (eosCRSwNP) was previously considered a minor subtype in Asian countries; however, recent evidence indicates a trend of continually increasing eosCRSwNP, ${ }^{5}$ which has even become the predominant subtype in China ${ }^{6,7}$ Traditionally, eosCRSwNP is associated with a higher recurrence rate than non-eosCRSwNP. On the other hand, a sub-set of patients with difficult-to-treat CRSwNP are characterized by severe and moderate neutrophilic inflammation, with elevated levels of interleukin (IL)-8, ${ }^{8}$ which itself raises the question regarding the role of neutrophils in the refractoriness of CRSwNP.

Corticosteroids are widely used in the treatment of CRSwNP due to their anti-inflammatory effects. However, high recurrence is frequently observed in eosCRSwNP patients in spite of receiving medical treatment (oral corticosteroid) and surgical treatment, indicating the treatment needs are not met in all patients. In this regard, several randomized, doubleblind, placebo-controlled studies have been performed, ${ }^{9}$ and there is increasing evidence to support that targeting eosinophils by binding soluble IL-5 (mepolizumab) and IL-5 receptor $\alpha$ (benralizumab) improve sinonasal symptoms and reduced nasal polyp (NP) size of patients, but not smell, asthma control or Sino-nasal Outcome Test (SNOT)-22 questionaire. ${ }^{10}$ In contrast, despite significantly reducing circulating and NP eosinophils, dexpramipexole (a steroid sparing compound) does not lead to reduction in NP size or improvement in sinonasal symptoms in CRSwNP. ${ }^{11}$ This further emphasizes inflammatory cells other than eosinophils, particularly neutrophils, might also in part contribute to the pathogenesis of eosCRSwNP.

Charcot-Leyden crystals (CLCs) are abundantly present in mucosa and mucus of eosCRSwNP patients, as a degradation product and marker of eosinophilic inflammation. In naïve C57BL/6 mice, an intratracheal injection of CLCs results in an influx of neutrophils into the airway lumen. ${ }^{12}$ In accordance with these observations, CLC-stimulated epithelial cells 
from CRSwNP patients have also been shown to significantly increase the migration of neutrophils, using a modified Boyden chamber assay. ${ }^{13}$ Although these findings suggest involvement of neutrophils in the pathophysiology of eosCRSwNP, to date the role of neutrophils in the development of CRSwNP remains unclear.

The diagnostic criteria of eosCRSwNP are subject to change with geographic and ethnic differences over time..$^{14}$ In the current issue, Kim et al. ${ }^{15}$ suggest how neutrophils and the relevant biomarkers, might contribute to the refractoriness of CRSwNP in the Asian population. NP and nasal tissue samples were analysed histologically, and eosinophilic $\mathrm{NP}$ and tissue neutrophilia ( $\mathrm{Neu}^{\text {high }}$ ) were respectively defined as more than 70 eosinophils and 20 human neutrophil elastase (HNE)-positive cells per high power field, whereas other samples were defined as non-eosinophilic NP and absence of tissue neutrophilia ( $\mathrm{Neu}^{\mathrm{low}}$ ). Based on this definition, 160 CRSwNP patients were divided into 4 groups: eosCRSwNP$\mathrm{Neu}^{\text {high }}(4.4 \%)$, eosCRSwNP-Neu ${ }^{\text {low }}(20.6 \%)$, non-eosCRSwNP-Neu high $(43.1 \%)$, and noneosCRSwNP-Neu ${ }^{\text {low }}(31.9 \%)$. Unsurprisingly, non-eosCRSwNP-Neu ${ }^{\text {low }}$ patients showed a higher rate of disease control than the other 3 groups, and tissue eosinophilia was correlated with a worse disease outcome. Furthermore, analysis the refractoriness trends of 4 groups using the linear by linear associations indicated that eosCRSwNP-Neu ${ }^{\text {high }}$ had an increased incidence of asthma in comparison with eosCRSwNP-Neu ${ }^{\text {low }}$ group, suggesting that neutrophilia was also associated with a worse outcome in CRSwNP.

Furthermore, binary multiple logistic regression analysis indicated that tissue neutrophilia was the strongest risk factor for CRSwNP refractoriness. To continually determine various relevant neutrophils-associated mediators on disease control, principal component analysis was performed. IL-18, interferon- $\gamma$, IL-1R $\alpha$, tumor necrosis factor- $\alpha$, oncostatin $\mathrm{M}$, and myeloperoxidase (MPO) cytokines were associated with good disease control status, whereas IL-36 $\alpha$ and IL-1 $\alpha$ cytokines were associated with refractory disease control status. Immunofluorescence staining also showed that among the HNE-positive cells, $\mathrm{IL}^{-36 \mathrm{R}^{+} \mathrm{HNE}}{ }^{+}$cells but not IL-36R ${ }^{+} \mathrm{MPO}^{+}$cells were significantly increased in the refractory group. As $\alpha 1$ anti-trypsin is known to be one of the potent inhibitors of HNE, this compound was also investigated as part of the study. The authors demonstrated that the ratio of HNEpositive cells to $\alpha 1$ anti-trypsin was also increased in the refractory group.

In conclusion, CRSwNP is a heterogeneous disease, the inflammatory profiles for which are influenced by geographic and ethnic differences of the affected individuals. In this respect, the higher level of tissue neutrophilia observed in Asian CRSwNP patients may influence the traditional treatment outcome as a result of any imbalance in HNE to $\alpha 1$ anti-trypsin ratio. However, large-scale, multicentre studies are required to further confirm the precise role of neutrophils in the pathophysiology and outcome of CRSwNP.

\section{REFERENCES}

1. Schiller JS, Lucas JW, Peregoy JA. Summary health statistics for U.S. Adults: national health interview survey, 2011. Vital Health Stat 10 2012:1-218. PUBMED

2. Hastan D, Fokkens WJ, Bachert C, Newson RB, Bislimovska J, Bockelbrink A, et al. Chronic rhinosinusitis in European underestimated disease. A GA²LEN study. Allergy 2011;66:1216-23. PUBMED | CROSSREF 
3. Kim JH, Cho C, Lee EJ, Suh YS, Choi BI, Kim KS. Prevalence and risk factors of chronic rhinosinusitis in South Korea according to diagnostic criteria. Rhinology 2016;54:329-35. PUBMED | CROSSREF

4. Lou H, Meng Y, Piao Y, Zhang N, Bachert C, Wang C, et al. Cellular phenotyping of chronic rhinosinusitis with nasal polyps. Rhinology 2016;54:150-9. PUBMED | CROSSREF

5. Jiang WX, Cao PP, Li ZY, Zhai GT, Liao B, Lu X, et al. A retrospective study of changes of histopathology of nasal polyps in adult Chinese in central China. Rhinology 2019;57:261-7. PUBMED | CROSSREF

6. Wang W, Gao Y, Zhu Z, Zha Y, Wang X, Qi F, et al. Changes in the clinical and histological characteristics of Chinese chronic rhinosinusitis with nasal polyps over 11 years. Int Forum Allergy Rhinol 2019;9:149-57. PUBMED | CROSSREF

7. Wang X, Zhang N, Bo M, Holtappels G, Zheng M, Lou H, et al. Diversity of $\mathrm{T}_{\mathrm{H}}$ cytokine profiles in patients with chronic rhinosinusitis: a multicenter study in Europe, Asia, and Oceania. J Allergy Clin Immunol 2016;138:1344-53. PUBMED | CROSSREF

8. Liao B, Liu JX, Li ZY, Zhen Z, Cao PP, Yao Y, et al. Multidimensional endotypes of chronic rhinosinusitis and their association with treatment outcomes. Allergy 2018;73:1459-69. PUBMED | CROSSREF

9. Bachert C, Han JK, Desrosiers M, Hellings PW, Amin N, Lee SE, et al. Efficacy and safety of dupilumab in patients with severe chronic rhinosinusitis with nasal polyps (LIBERTY NP SINUS-24 and LIBERTY NP SINUS-52): results from two multicentre, randomised, double-blind, placebo-controlled, parallel-group phase 3 trials. Lancet 2019.394:1638-50. PUBMED | CROSSREF

10. Gevaert P, Van Bruaene N, Cattaert T, Van Steen K, Van Zele T, Acke F, et al. Mepolizumab, a humanized antiIL-5 mAb, as a treatment option for severe nasal polyposis. J Allergy Clin Immunol 2011;128:989-995.e1-8. PUBMED | CROSSREF

11. Laidlaw TM, Prussin C, Panettieri RA, Lee S, Ferguson BJ, Adappa ND, et al. Dexpramipexole depletes blood and tissue eosinophils in nasal polyps with no change in polyp size. Laryngoscope 2019;129:E61-6. PUBMED | CROSSREF

12. Persson EK, Verstraete K, Heyndrickx I, Gevaert E, Aegerter H, Percier JM, et al. Protein crystallization promotes type 2 immunity and is reversible by antibody treatment. Science 2019;364:eaaw4295. PUBMED | CROSSREF

13. Gevaert E, Delemarre T, De Volder J, Zhang N, Holtappels G, De Ruyck N, et al. Charcot-Leyden crystals promote neutrophilic inflammation in patients with nasal polyposis. J Allergy Clin Immunol. Forthcoming 2019. PUBMED | CROSSREF

14. Lou H, Zhang N, Bachert C, Zhang L. Highlights of eosinophilic chronic rhinosinusitis with nasal polyps in definition, prognosis, and advancement. Int Forum Allergy Rhinol 2018;8:1218-25. PUBMED | CROSSREF

15. Kim DK, Kim JY, Han YE, Kim JK, Lim HS, Eun KM, et al. Elastase-positive neutrophils are associated with refractoriness of chronic rhinosinusitis with nasal polyps in an Asian population. Allergy Asthma Immunol Res 2020;12:42-55. CROSSREF 